\title{
Alimentação, Artes e Ensino de Ciências: articulação para a formação de professores
}

\begin{abstract}
Resumo: A valorização dos sentidos e a apreciação dos sabores são de extrema importância para a alimentação, seja na degustação ou no preparo dos alimentos. Atualmente vivemos numa cultura visual e auditiva, que subjuga as experiências que envolvem proximidade, como tocar, cheirar e provar. É preciso investir em ações educativas que resgatem o prazer da apreciação dos sabores dos alimentos naturais, sendo a escola um espaço profícuo para tal intento. Este trabalho objetiva compor discussão teórica para a proposta da Educação dos sentidos, apresentando como exemplo desta prática uma experiência de oficina de formação de professores de ciências. Diferentes formas de artes atuaram como mediadoras para estimular a sensibilização dos sentidos. Durante as etapas da atividade os professores se surpreenderam com novas percepções de sabores e sensações, com as diferentes dimensões da alimentação e expuseram os desafios para a articulação em suas práticas docentes do tema apresentado na oficina.
\end{abstract}

Palavras-chave: Educação alimentar. Educação sensorial. Ensino de ciências. Formação de professores. Oficina de artes.

\section{Introdução}

O trabalho aqui exposto se constitui como o relato da fase exploratória de uma pesquisa. "Compreende a etapa de escolha do tópico de investigação, de delimitação do problema, de definição do objeto e dos objetivos, de construção do marco teórico-conceitual, dos instrumentos de coleta de dados e da exploração do campo". (MINAYO, 1992, p. 89) Por esse caminho exploratório, serão desenvolvidas a seguir as bases teóricas com suas articulações possíveis para fundamentar os propósitos de um dos subtemas desta pesquisa: alimentação. Como objetivo principal, a investigação exposta neste trabalho almeja analisar o tema "alimentação" como mobilizador da articulação entre ciência e cultura extraescolar e também intenta examinar maneiras de integrar às práticas de formação continuada de professores de ciências diversos tipos de expressão de arte como mediadoras de sensibilização e criatividade para os processos de ensino-aprendizagem que se articulam à Educação Alimentar e Nutricional (EAN) em contexto escolar. O recorte exposto neste trabalho objetiva compor discussão teórica para a proposta da Educação dos sentidos explicitada adiante no
Mônica Alves Lobo Universidade Federal do Estado do Rio de Janeiro (UNIRIO) lobo.monica@gmail.com Guaracira Gouvêa de Sousa Universidade Federal do Estado do Rio de Janeiro (UNIRIO) 
texto, apresentando como exemplo desta prática uma experiência de oficina de formação de professores de ciências.

Para essa finalidade, são necessárias reflexões sobre como se concebem os gostos (do ponto de vista de estética e do paladar) e as maneiras pelas quais podemos educá-los em processos de ensino-aprendizagem de ciências articulados à cultura alimentar e suas práticas. Tais reflexões constituem os dois itens seguintes do texto, complementados pelo relato de uma experiência de formação continuada de professores que colaborou com a elucidação de caminhos a serem seguidos nas fases posteriores do projeto de pesquisa.

\section{Os sentidos, os sabores e a saúde}

Os sentidos do tato, paladar, audição, visão e olfato são de extrema importância nos processos que envolvem o ato de comer: as sensações térmicas e a consistência dos alimentos; os sabores como o salgado e o amargo; os ruídos de crocância e de estalar língua e lábios; o aspecto e cor dos alimentos; o aroma agradável que atrai a atenção ou o desagradável que gera repulsa. (NASCIMENTO, 2007) A cor, a textura e o som exercem um papel marcante na degustação dos alimentos, estando reservado ao gosto, caracterizado pela percepção de sabor, odor, frescor e pungência um maior destaque para a caracterização do prazer de comer. (AHN et al., 2011) Entretanto, estamos vivendo atualmente dinâmicas culturais extremamente visuais e auditivas, que subjugam as experiências que envolvem proximidade, como tocar, cheirar e provar. (CARVALHO, 2011) Michel Serres (2001) afirma que dos cinco sentidos, o olfato e o paladar são os que nos parecem menos estéticos, são os sentidos da proximidade, considerados até mais animalescos. A boca que sente adormece sob o jugo da boca que fala. A linguagem manifesta no excesso de fala e comunicação adormece o paladar, a sensibilidade tátil. Mas é a sensação que inaugura a inteligência. "Não há inteligência emocional. A inteligência jamais procura a emoção. É a emoção que procura a inteligência. É a emoção que deseja ser eficaz para realizar o sonho". (ALVES, 2005, p. 20)

Atualmente, a boca que sente os sabores, referida por Michel Serres, segue negligenciada pelo excesso de uso da boca que fala e mantem-se hiperestimulada pelos aditivos químicos dos produtos alimentícios industrializados que tornam essa boca insensível aos 
suaves sabores da comida de verdade. Essa expressão foi apresentada pela primeira vez na $5^{\text {a }}$ Conferência Nacional de Segurança Alimentar e Nutricional ocorrida em 2015, após a publicação de dois documentos fundamentais para a EAN: o Marco de Referência de Educação Alimentar e Nutricional para as Políticas Públicas (2012) e o Guia Alimentar para a População Brasileira (2014). A partir da conferência de 2015, foi publicado um manifesto que visa expressar a complexidade e a importância da expressão comida de verdade. (BRASIL, 2015) Comida de verdade começa no aleitamento materno, é caracterizada por alimentos in natura e minimamente processados. É produzida pela agricultura familiar, com base agroecológica e com o uso de sementes crioulas e nativas, é livre de agrotóxicos, de transgênicos, de fertilizantes e de todos os tipos de contaminantes. Comida de verdade garante a soberania alimentar, é produzida com justiça social, protege o patrimônio cultural e genético; reconhece a memória, a estética, os saberes, os sabores, enfim, a cultura. E defende que comer é um ato político.

O tempo que poderia ser utilizado para cozinhar e sentir os sabores dos alimentos in natura tem sido despendido com programas de TV sobre culinária. Com a cultura da falta de tempo estabelecida, assistir a alguém cozinhando na TV nos oferece um alento ilusório de que estamos participando do ato de cozinhar e que estamos de fato nos conectando com outros seres humanos, enquanto na verdade a noite termina com algum produto alimentício industrializado congelado sendo aquecido no micro-ondas para o jantar. (PACHECO, 2003; POLLAN, 2014)

Cozinhar nos define como seres humanos, é uma atividade que nos conecta uns com os outros, pois "o toque poderia ser considerado a forma precursora da linguagem, que vai sendo aprimorada com o tempo, passando para um registro simbólico". (MACHADO; WINOGRAD, 2007, p. 471) Nossas experiências táteis nos conectam e produzem memórias de saber e de sabor. Dessa forma, se o cozinhar é apenas admirado em telas de TV e celulares, mas não é realizado enquanto processo de trocas afetivas e construção de sabores e culturas dentro da cozinha, permanecemos distraídos pela ilusão das imagens enquanto veículo de saúde per si.

Para a realização da experiência do comer de forma íntegra, é preciso que nossos sentidos estejam todos despertos para detectar as sutilezas e a riqueza de saborear um alimento ou uma refeição. O ato de cozinhar, tão bem lapidado pela Gastronomia, constitui-se 
como uma forma de se comunicar, se conectar e partilhar afeto com o outro. A Gastronomia em si se manifesta como a culinária elevada ao estado de arte, despertando sentidos, sensações e emoções ou como uma ciência que se equivale às outras de grande importância, mas que, diferente das demais, reforça o vínculo entre as pessoas, mediando eventos sociais e contextos afetivos dos quais participamos durante toda a vida. (MACHADO; WINOGRAD, 2007; SAVARIN, 1995)

Temos uma tendência fisiológica a preferir alimentos doces e ricos em gordura em relação aos alimentos salgados, ácidos, picantes e especialmente aos amargos. (AHN et al., 2011) Esse fato favoreceu a sobrevivência da espécie humana por muito tempo. Entretanto, a partir do século XX o consumo de açúcar aumentou em cerca de dez vezes e, associado a interesses socioeconômicos e mudanças no estilo de vida das populações urbanas, fez emergir várias patologias crônicas que impactam cada vez mais a saúde dessas populações. (CONTRERAS; GRACIA, 2011; GARCIA, 1994) Louzada e demais autores (2015) em estudo transversal demonstraram as tendências do consumo alimentar brasileiro atual. Os alimentos ultraprocessados já representam $21,5 \%$ do consumo diário de pessoas acima de 10 anos de idade, com tendência crescente. Se comparados aos alimentos in natura ou minimamente processados, os alimentos ultraprocessados têm cerca do dobro de calorias e açúcares, oito vezes mais gorduras trans, três vezes menos fibras e cerca de duas vezes menos proteínas e potássio.

Segundo a dietética da Medicina Tradicional Chinesa (MTC), uma das questões importantes para o equilíbrio da saúde é a ingestão equilibrada dos cinco sabores - doce, salgado, ácido, amargo e picante - identificados de igual maneira como essenciais a nossa saúde. (FAHRNOW; FAHRNOW, 2003; PERINI, 2003) Mas esse entendimento sobre os sabores é um pouco diverso do que costumamos partilhar na cultura ocidental. Para nós ocidentais, os alimentos doces e salgados costumam ser associados àqueles adicionados de açúcar e sal, como um brigadeiro ou uma carne de sol, enquanto que para a dietética da MTC, além desses - considerados numa condição de sabor "tóxico" -, a couve-flor é um alimento doce e a berinjela um alimento salgado, por exemplo. Com base no conhecimento biomédico que norteia o entendimento de saúde no ocidente, damos atenção especial à composição química dos 
alimentos ingeridos e às interações desses elementos com o nosso corpo, não nos focando nos sabores e suas relações com a saúde.

Ao longo do desenvolvimento dos conhecimentos milenares da MTC, os alimentos foram classificados segundo seus sabores naturais anteriores a qualquer processamento ou técnica culinária de preparo. Esses conhecimentos tradicionais orientais dos sabores dos alimentos somados aos conhecimentos biomédicos da relação entre composição química e fisiologia podem nos oferecer uma base rica para ampliarmos nossa percepção e autonomia sobre nossos hábitos alimentares para realizarmos escolhas cada vez mais saudáveis. (BRASIL, 2012) E apesar desses conhecimentos sobre alimentação do ponto de vista da tradição oriental ainda não habitarem o ambiente escolar para a ampliação das práticas de Educação Alimentar e Nutricional (EAN), as práticas integrativas e complementares para a saúde já são realidade no SUS, contribuindo para a qualidade de vida de milhões de brasileiros. (BRASIL, 2015)

A adição de sal, açúcar e gordura saturada constitui prática que baseia a produção dos alimentos ultraprocessados tão consumidos atualmente e tão maléficos à saúde. (BRASIL, 2014) Os indivíduos que se alimentam desses produtos na maior parte do tempo vão perdendo a percepção mais sutil dos sabores naturais - doce, salgado, amargo, picante e ácido - e deixam de comer os alimentos in natura que os representam, subutilizando nossa fantástica capacidade de saborear e nos adaptar a uma enorme variedade de sabores, cheiros e texturas. (CONTRERAS; GRACIA, 2011; GARCIA, 1994) Esse desequilíbrio contribui, dentre outros fatores, para o baixo consumo de muitos alimentos frescos como os vegetais folhosos, as frutas cítricas e ervas aromáticas, por exemplo, sem os quais deixamos de nos nutrir com tantas vitaminas, fibras e sais minerais e nos privamos da experiência de realizar e saborear tantas receitas culinárias maravilhosas. Ao invés disso, intoxicamos nossos sentidos com os sabores sintéticos dos aditivos químicos e ingerimos alimentos extremamente saturados em açúcar, sal e gordura que sustentam um sistema (também produtivo e econômico) viciante no centro de prazer do cérebro, nos levando a querer mais e mais destes alimentos indefinidamente. (SAWAYA; FILGUEIRAS, 2013) Pollan (2014, p. 17) alerta sobre essa artificialidade afirmando que "de fato, a ideia de que a comida possa ter algum vínculo com a natureza, com o trabalho humano ou com a imaginação não é nada óbvia quando ela chega inteira dentro de uma embalagem". 
A saciedade humana está relacionada com a quantidade de alimentos ingeridos, com a variedade de sabores, cheiros, cores e texturas, entre outros fatores fisiológicos. O nosso corpo identifica através dessa interação sensorial a ingestão adequada dos nutrientes necessários à manutenção da saúde. (AHIMA; ANTWI, 2008) Outros fatores como as interações sociais, afetivas, questões culturais, o acesso e a disponibilidade de alimentos também determinam nossa ingestão alimentar. (CONTRERAS; GRACIA, 2011; GARCIA, 1994; JOMORI; PROENÇA; CALVO, 2008)

Atentos às diferenças marcantes entre as receitas culinárias tradicionais de países do oriente e do ocidente e ao número limitado de combinação de ingredientes diante da enorme variedade possível, Ahn e demais autores (2011) mapearam quimicamente os sabores de 381 ingredientes de receitas de diferentes partes do mundo. Segundo a hipótese da pesquisa -inspirada na teoria chamada food pairing -: ingredientes que compartilham compostos semelhantes tem maior palatabilidade juntos. Essa hipótese tem levado cientistas e chefs de cozinha a buscarem e testarem novas combinações de ingredientes.

Os pesquisadores encontraram como um dos resultados que as receitas dos países do oriente tendem a ser compostas por alimentos de sabores contrastantes e as do ocidente, por alimentos de sabores similares. No estudo foi relatado que a culinária norte-americana, por exemplo, é composta prioritariamente por laticínios, ovos e trigo - base de muitos alimentos ultraprocessados - e a do leste asiático por derivados vegetais como molho de soja, óleo de gergelim, arroz e gengibre. Os pesquisadores sugerem uma relação entre uma alimentação com monotonia de sabores e o aumento da ingestão de alimentos, com consequentes prejuízos à saúde, como o desenvolvimento de obesidade e comorbidades relacionadas.

O contato direto com os alimentos na cozinha e a apreciação mais atenta aos sabores e demais características sensoriais desses alimentos são estimulados através do afeto. Tanto cozinhar quanto comer fazem parte de processos que envolvem o estabelecimento de vínculos afetivos, de prazer e o desenvolvimento da criatividade e sensibilidade. Dessa maneira, é de vital importância para o desenvolvimento de hábitos alimentares saudáveis o investimento na Educação dos sentidos que nos motiva a ter experiências singulares de sensações e produção de memórias sensoriais cujo percurso nos leva a aquisição de uma nova consciência sobre estas experiências, 
sobre nós mesmos e o que as compõe. Essa constante experimentação nos estimula a sempre buscar novidades e ampliar nossas perspectivas em relação ao mundo que nos cerca.

Quanto mais conhecermos e apreciarmos os sabores e as sensações provocadas por alimentos naturais e variados, mais deixamos de nos iludir com a busca por novidades sugerida pela publicidade da indústria de alimentos. A ilusão está na crença de que as embalagens novas trazem alimentos novos. Geralmente trata-se apenas da mudança de algum aditivo alimentar artificial que objetiva gerar um aumento do consumo.

\section{A educação dos sentidos no ensino de ciências}

Educar os sentidos (SILVA; SAKAMOTO; GALIAN, 2014) se faz através da apreciação e do deslumbramento provocados pela arte. A arte é uma linguagem universal que amplia a sensibilidade humana e a consciência diante do mundo, sendo um valioso mediador para processos de aprendizagem. (FIGUEIRA-OLIVEIRA et al., 2007; FIGUEIRA-OLIVEIRA; LOPES, 2005; FIGUEIRA-OLIVEIRA; ROCQUE; MEIRELLES, 2009) Através da arte manifestamos nossa cultura e a imensa variedade de formas de significá-la. Nesse caso, podemos ampliar os sentidos sobre a alimentação nos contextos educativos por meio de práticas de EAN nas quais as diversas maneiras de manifestar arte nos oferecem um prodigioso universo de possibilidades para sentir, produzir novas representações e compartilhar conhecimentos e percepções com os indivíduos que interagem conosco. Professores e alunos com percepção sensível e criatividade aguçada podem conseguir mais facilmente participar do processo de ensino-aprendizagem. (BRASIL, 1997)

Michel Serres (2001, p. 154) divide a nossa boca em duas: a boca do discurso e a boca do gosto. "A palavra, qual uma rainha, reina em seu palato", subjugando a percepção dos sabores. Somos tagarelas sem atenção às sensações possíveis que vão além da articulação racional dos pensamentos. O autor resgata nosso título de Homo sapiens em seu significado semântico primordial, o de sermos seres que apreciam a busca, que dão valor ao sentido do gosto, à sapidez. Afirma que a sabedoria não pode vir antes do sabor: "o bicho come depressa, o homem saboreia". (SERRES, 2001, p. 155) O pensamento desarticulado da percepção elabora sínteses, sedimenta ideias, constrói conceitos. As percepções sensoriais diferenciam, 
ampliam, multiplicam. A anestesia dos sentidos nos rouba a estética, a apreciação, o encantamento pelo novo, tão imprescindíveis para a concepção do conhecimento científico.

A sensibilização e a criatividade que a arte inspira ajudam a promover a percepção individual sobre o comer através do refinamento dos sentidos e da apreciação dos sabores. O processo de ensino-aprendizagem é um espaço-tempo propício à promoção da integração entre essas percepções individuais e as demais dimensões da alimentação - questões de saúde pública, sociais, econômicas e culturais - e ao estímulo à compreensão do mundo através da totalidade dos sentidos, estabelecendo uma relação intrínseca entre a racionalização e a emoção, a expressão corporal e a manifestação verbal, a experimentação prática e elaboração teórica. (BRASIL, 1997; BRASIL, 2013) A abordagem do tema alimentação em sala de aula, em especial no contexto do Ensino de Ciências (EC), não pode prescindir deste tipo de articulação, com o risco da repetição da insuficiente abordagem fisiológica da alimentação na qual se trata a saúde como consequência da adequada assimilação de nutrientes pelo corpo. (BRASIL, 2014; FERNANDEZ; OLIVEIRA, 2008; FREITAS; MARTINS, 2008, MOHR, 1995)

É preciso citar um exemplo de obra de arte que nos instiga a conexão dos sentidos e percepções particulares com questões mais abrangentes. "Perfect Sense" (2011) é um filme exemplar nesse sentido. A história é construída a partir da expectativa crescente do fim da humanidade ameaçada por um vírus que "desliga" progressivamente os sentidos do paladar, olfato, audição e visão. Em cada fase da epidemia, o desligamento de um sentido é conectado à "explosão" de um sentimento específico. O extravasamento das emoções em níveis nunca antes experimentados e a progressiva perda da capacidade de sentir o mundo vão causando um colapso social. Os protagonistas são um chefe de cozinha com perfil mais passional e inconstante (o ser criativo e livre: o artista) e uma epidemiologista melancólica e cética (o ser racional e encarcerado: a cientista). O encontro entre os dois muda suas vidas e transforma cada um em algo mais do que estereótipos engessados. Eles se conectam e experimentam as sensações e os sentidos múltiplos de ser humano.

Ciência e arte parecem dois campos distintos, pois um busca o racional e o outro, o sentimento; um descreve friamente, o outro declama poesias; um registra dados 'objetivos', o outro se 
encanta; um matematiza a natureza, o outro percebe o todo; um procura explicar, o outro a interpretação; um se diz 'objetivo', o outro é todo 'subjetivo'. Mas será que são campos realmente distintos? (LENZI, 2004, p. 73)

Atualmente, os conhecimentos dos avanços científicos e tecnológicos, as questões ambientais e da globalização da economia e da cultura, dentre outras, constituem um complexo sistema a ser compreendido para a prática de escolhas alimentares mais saudáveis. (CONTRERAS; GRACIA, 2011; GARCIA, 1994) A partir da articulação entre arte e ciência podemos produzir processos de ensino-aprendizagem por meio dos quais seja possível apresentar a alimentação em toda sua complexidade, como produto cultural humano. Nós, munidos de nossos conhecimentos, tecnologias e sensibilidade podemos nos alimentar melhor e participar de contextos de produção, distribuição e consumo mais adequados à vida humana e à preservação do meio ambiente. Podemos agir como seres criativos unindo o conhecimento científico e as emoções, a técnica e os sentidos, referências históricas, geográficas, econômicas e filosóficas. (FIGUEIRA-OLIVEIRA, 2007; BARBOSA et al., 2013)

O fato da ciência moderna ter descartado os elementos clássicos (fogo, água, ar e terra), reduzindo-os a substâncias e forças ainda mais elementares [...] na realidade não mudou nossa experiência em relação à natureza do modo como a vivenciamos ou a imaginamos. (POLLAN, 2014, p. 20)

Jomori, Proença e Calvo (2008) nos caracterizam como comedores biológicos e culturais, cuja escolha alimentar é determinada pela fisiologia, patologia, genética, sexo, idade, sensibilidade sensorial; e na cultura, por experiências familiares, status social, tradição alimentar, meio ambiente, personalidade, emoções, questões morais e religiosas. Ademais, para saborearmos alimentos naturais é preciso ter acesso tanto do ponto de vista geográfico como econômico. E para que esses alimentos sejam saudáveis, é necessário que as formas de produção respeitem o meio ambiente e promovam a justiça social. Também é de fundamental importância o respeito e resgate de culturas alimentares tradicionais e os modos de produção dessas culturas através do registro histórico e das práticas culinárias em si. (BRASIL, 2014)

A alimentação está presente nas orientações curriculares nacionais (BRASIL, 1997, 2006) como tema transversal inserido no grande 
tema saúde. Um dos objetivos é orientar para que a alimentação seja uma temática integrante de todas as disciplinas, não estando a sua abordagem restrita à disciplina de Ciências ou Biologia. Ademais, o novo Guia alimentar da população brasileira (BRASIL, 2014) orienta que extrapolemos o entendimento da alimentação como uma relação entre nutrientes classificados em categorias e associados a funções fisiológicas e patologias e abordemos a questão de forma a contextualizá-la em relação à realidade de vida dos indivíduos. As situações escolares cotidianas também desafiam os professores a discutir o tema alimentação para além dos conteúdos insuficientes dos livros didáticos (FERNANDEZ; OLIVEIRA, 2008; FREITAS; MARTINS, 2008; MOHR, 1995), exigindo destes profissionais conhecimentos e capacitação para elaborar atividades que atendam ao mesmo tempo o conteúdo curricular, a contextualização do tema e a articulação com outras disciplinas. (LOBO, 2014)

O tema alimentação funciona como um articulador também para reflexões e discussões sobre questões contemporâneas e urgentes, tais como: a produção de alimentos e degradação ambiental, os estilos de vida, as escolhas alimentares e as repercussões desses movimentos na dinâmica da economia e nas dinâmicas sociais; o conhecimento como recurso para o cuidado com a saúde. (BARBOSA et al., 2013)

\section{Oficina para formação de professores: articulando os saberes}

O presente texto foi elaborado a partir do recorte de um projeto de pesquisa financiado pelo edital Universal/ Conselho Nacional de Desenvolvimento Científico e Tecnológico (CNPq). Um dos objetivos da segunda etapa do projeto foi desenvolver e oferecer atividades de formação para professores de ciências de três municípios do estado do Rio de Janeiro (Macaé, Angra dos Reis e Cabo Frio) com foco na articulação entre ciência e arte. Além da oficina articulando alimentação, ensino de ciências e arte descrita neste trabalho, foram realizadas oficinas articulando Ensino de Química e teatro, Ensino de Biologia e cinema, Ensino de Física e música, Ciência, Tecnologia, Sociedade e Ambiente (CTSA) e artes visuais. Outro objetivo estabelecido foi a construção de parcerias para discussões coletivas entre pesquisadores e professores de ciências 
dos municípios selecionados para o desenvolvimento de novos conhecimentos e abordagens pedagógicas.

A oficina relatada neste trabalho foi oferecida por um período de quatro horas a um grupo de trinta e cinco professores de ciências no município de Cabo Frio-RJ em um centro de formação disponibilizado através de contato com a Secretaria de Educação. Cada professor presente no centro de formação participou de duas oficinas, uma no período da manhã e outra à tarde, com a mesma duração de quatro horas, todas articulando alguma expressão de arte (cinema, teatro, música, fotografia/artes plásticas) às questões científicas trabalhadas no currículo, com a proposta de produzir conjuntamente reflexões sobre integrar novas práticas e ferramentas didáticas no exercício docente destes professores de ciências.

\section{A dinâmica da oficina}

Cinco etapas de experiências de percepção sensorial constituíram a oficina: 1 - Poemas e sabores; 2 - Aromas e memórias; 3 - As Imagens têm gosto; 4 - Mapa dos alimentos; 5 - Os sentidos dos sons. Cada etapa foi pensada para contemplar a dimensão de um dos cinco sentidos (paladar, olfato, visão, tato e audição), além dos cinco sabores (doce, salgado, azedo, amargo e picante), e para ser constituída por diferentes expressões de arte. Dessa forma a sensibilidade e criatividade que a arte faz transbordar em nós poderia auxiliar a experimentação através dos sentidos que demandam tranquilidade, atenção e receptividade.

Na primeira etapa "Poemas e sabores" os professores foram convidados a fechar os olhos, relaxar e escutar a declamação de cinco poemas extraídos do livro "A poesia é para comer". (VIDAL, 2011) Foram selecionados poemas que representavam cada um dos cinco sabores. Os professores foram orientados a experimentar o poema, a escutar os versos e buscar o sabor de cada um e o gosto de cada poema inteiro. Após as declamações os professores foram calmamente abrindo os olhos e retomando contato com os demais componentes do grupo, ficando livres para expressar suas sensações se desejassem. Essa etapa foi importante para o relaxamento e conexão inicial à atividade e às próprias memórias sobre o comer.

Na etapa seguinte chamada de "Aromas e memórias", alguns professores foram voluntários para utilizar uma venda nos olhos e tentar descrever como era o aroma sentido dos condimentos ou óleos essenciais oferecidos na dinâmica. Esses professores foram 
também estimulados a descrever as sensações e lembranças associadas àqueles cheiros. Os demais participantes também puderam sentir os aromas livremente e contribuíram com suas memórias e impressões. Um dos professores falou após sentir o aroma de funghi seco: "eu sinto um cheiro forte de madeira de terra... como fui uma criança muito tranquila (risos) me lembra muita coisa, muita arte que eu fiz". Uma professora em seguida relata, emocionada, sua memória ao cheirar curry: "eu não sei o que é isso, mas colocaria na minha papa... me lembra como se fosse canela... é senti um cheirinho de canela mas acho que não é... é que eu sou nordestina tá todo mundo lá comendo papa com canela menos eu agora".

Na parte "As imagens tem gosto" foi mostrada uma sequência de ilustrações, fotografias e pinturas com temáticas relacionadas aos cinco sabores, como por exemplo: "Cacau - série de frutos" de Genaro de Carvalho (1967); "Pequena moenda de cana-de-açúcar" de Debret (1835); um desenho de botânica sobre canela "Salmon sea" de Carl Warner'; "Natureza morta com papagaio" de Frida Kahlo (1951). A cada imagem exibida foi questionado aos professores: que gosto tem essa imagem? A partir da maior parte das imagens os professores se concentraram mais em adivinhar o sabor, ou seja, a resposta certa. A pintura de Debret que retrata o trabalho escravo em lavoura de cana-de-açúcar fez emergir um comentário sobre a relação entre trabalho docente e exaustão, o sabor amargo do trabalho, o cheiro azedo da exploração. O comentário foi prontamente acolhido pelos demais professores.

A imagem que realmente despertou discussão longa entre os professores foi uma fotografia de coentro. Uma das professoras refletiu sobre a relação entre o consumo de vegetais e emagrecimento, uma associação direta entre alimentação saudável e falta de prazer na alimentação:

tá sempre associada a regime você não acha? a salada a fruta normalmente eu estava vendo uma reportagem sobre dieta, que isso passa o tempo todo né? você seca muito rápido e tudo e não tem essa é exatamente isso você tem muito legume muita fruta muito verde, tira todo o outro né e você começa a criar uma uma alimentação que não é é é natural né? não é é fica uma semana vai enjoar todo os dias não tá acostumado começa aquilo tipo assim e [sic] a gente sempre comenta do mal que faz mas também não fala dessa questão do prazer, do prazer do equilibrar isso e quando a gente também trata disso em sala de aula a gente também trata dessa maneira 
distanciada né? que seria comer saudável e não uma coisa prática não uma coisa a gente sempre fala não isso aqui é saudável cria um imaginário como se não existisse aquilo na vida real.

Outra professora complementa a discussão sobre hábitos alimentares saudáveis apontando as dificuldades encontradas pelos alunos para se alimentar no cotidiano:

eu dou aula no $8^{\circ}$ ano [sic] a gente sempre comenta quando a gente vai começar sistema digestório é... com cardápio o quê que eles comem muitos não comeram naquele dia a maioria dos alunos não tem o habito de tomar café da manhã a gente conta nos dedos os que se alimentam de manhã antes de vir para a escola porque 8:40h eles tem um um é... um lanche então eles deixam para comer aquele lanche ali da escola que às vezes é um iogurte às vezes é um pão com requeijão ou com goiabada e os que não comem aquilo só vão comer meio-dia [sic] quando termina e vão comer ali a merenda da escola ou vão para casa sem ter comido NADA durante a manhã inteira e a maioria deles não come nada e há ainda aqueles que comem um salgado que é vendido na escola você tem um ou dois que tomam café porque os pais na maioria estão dormindo então ninguém acorda pra fazer o café para eles os pais não ensinam para eles que eles precisam comer antes de ir para a escola porque nem os pais comem.

Após essas atividades de experimentação sensorial, os professores foram convidados a montar o "Mapa dos alimentos". Com diferentes tipos de alimentos representados por cartões, os professores foram orientados a agruparem os alimentos de acordo com a similaridade de sabor, assim, alimentos doces ficariam agrupados com doces, salgados com salgados etc. No fim da montagem do mapa (Figura 1), discutimos o resultado e os sentidos produzidos ao longo da atividade.

Inicialmente os professores tenderam a agrupar de acordo com o sabor que cada um supunha a partir do alimento descrito nas fichas. Mas na medida em que alguém acrescentava um alimento por grupo alimentar (fruta perto de fruta), a tendência foi que os demais seguissem a nova (já conhecida) categorização. É possível ver na imagem do meio (Figura 1) o agrupamento, no início da atividade, de alimentos considerados naturalmente doces (fígado, frango, shitake) seguidos por alimentos sabidos como fontes de proteína. O mesmo ocorreu com as bebidas na imagem à esquerda e com os condimentos (imagem da direita e da esquerda) e as 
frutas na imagem à direita, independente do sabor mais doce ou mais ácido desses alimentos.

Figura 1: mapa dos sabores montado pelos professores na oficina Fonte: fotografia registrada pela equipe do projeto

Essa seleção de alimentos para a atividade foi inspirada no trabalho de Ahn e demais autores (2011), com o objetivo de também discutir os contrastes dos ingredientes mais utilizados nas culinárias ocidentais e orientais. Alguns ingredientes causaram dúvidas por desconhecimento (mirtilo) ou por estranhamento (rosa). As questões foram sendo esclarecidas ao longo da dinâmica. Nesse ponto da oficina, foi reforçada a ideia do equilíbrio dos cinco sabores e a importância de estimularmos essa percepção no dia a dia para escolhas alimentares mais saudáveis. Alguns professores levantaram a discussão sobre a influência da família nos hábitos alimentares das crianças e da importância de, mesmo não apreciando muito determinado alimento, oferecê-lo às crianças e tentar também prepará-lo de formas diferentes para conhecer o próprio gosto e talvez mudar de ideia, integrando o novo alimento às refeições. Em seguida, tivemos um momento para que os professores tirassem dúvidas sobre os próprios hábitos alimentares.

Para encerrar a oficina de maneira a reiterar os sentidos e os sabores da alimentação na escola e fora dela, houve a apresentação de um número musical da obra intitulada "Sentidos dos Sabores", composta previamente para a realização da atividade, de autoria de dois participantes da organização da oficina. A letra segue abaixo:

\author{
SENTIDOS DOS SABORES \\ (2015) \\ Que sentidos tem a vida? \\ Senão ouvir o zumbido \\ de abelhinhas bem docinhas \\ à beira do meu ouvido \\ Ou seria provar a fome \\ no ventre amargo da sociedade louca, \\ vestígios de humanidade \\ à beira da minha boca? \\ Talvez seja tocar o manto \\ da escama fria de um namorado \\ Sal, fogueira e paixão
}


no veludo quente da minha mão

Que sentidos tem a vida?

Mel, melado, melodia

Sabor de som semeado

Pra almoçar ao meio-dia

Imagina se é sentir perfume

de bergamota ácida e faceira

Gargalhadas e cócegas no ato

Festejando alegre o meu olfato

Acho mesmo que já vi, vivi, revivi

todo o ardido coroando o mar

Poente, Pitanga, manga, canga, tanga, zanga, sangra dedos de moça

Regalo-me extasiado só de olhar

Que sentidos tem a vida?

Cheiro, língua e toque são, lampião

Tem também canção e luz

Para adoçar nosso sertão

Após todas as atividades, os professores realizaram a avaliação da oficina. Seguem alguns depoimentos abaixo (nomes fictícios identificam os professores):

Marisa: Harmoniosa, doce, picante, cítrica, informativa, saborosa, colorida, novidade, temperado, despertamento para os diferentes sabores, relação entre os órgãos dos sentidos, diferenciada, dinâmica, comparativa, diversidade de informações, diferentes sabores, cheiros, interessante, colorida, musical.

Tereza: Simplesmente foi maravithoso, percebi o quanto não sabia associar e equilibrar os sentidos e sabores. Posso dizer que a partir de hoje terei um olhar mais criterioso na preparação dos alimentos e mais, terei o cuidado em passar este aprendizado.

Elizabete: Para mim foi válido, porque aprendi sobre a alimentação ligada aos sentidos, eu nunca ouvi falar sobre esse tema, apesar de sempre ensinar aos meus alunos que os sentidos "ligam e desligam" o sistema reprodutor. Agora posso usar e fazer essa ligação para o alimento.

Rubens: Particularmente adorei a oficina. As possibilidades para debate e discussão foram amplas e bem proveitosas. Nesse sentido, vi a oficina como ideias/possibilidades de dinamizar nossas aulas e práticas laboratoriais. A única sugestão/crítica seria a elaboração de material (físico) para utilização em sala de aula. 


\section{Considerações finais}

Foi elaborada uma proposta de formação durante a qual os professores puderam vivenciar a questão alimentar na perspectiva da Educação dos sentidos. Diferentes expressões de arte mediaram a aprendizagem e o estímulo à sensibilidade. O foco nas percepções sensoriais auxiliou na problematização de concepções que dissociam alimentos saudáveis ao prazer de comer, gerando debates que articularam questões da vida cotidiana com os conhecimentos construídos em sala de aula com os alunos. Os alimentos observados através da lente da arte trouxeram aos professores uma perspectiva mais ampla sobre os sentidos da alimentação, extrapolando os conhecimentos sobre a relação destes alimentos com o corpo.

Através da Educação dos sentidos podemos vivenciar experiências múltiplas e ricas, nos tornando sensíveis à delicadeza que exige a apreciação do sabor de uma fruta tão sutil como a pêra ou um vegetal de sabor inusitado e intenso como o agrião. Com a sensibilidade aguçada podemos de fato decidir o que gostamos ou não e como gostamos de preparar e degustar determinado alimento ou preparação culinária. Essas possibilidades foram postas à disposição dos professores de ciências presentes na oficina, que se deliciaram com a experiência cada qual a sua maneira, levando para casa aprendizagem e estímulo para desbravar novas práticas alimentares que colaboram para a manutenção da saúde.

Algumas questões apontadas merecem destaque: os professores pediram para que as próximas oficinas tenham uma etapa inicial de aprendizagem dos sabores dos alimentos com base nos conhecimentos da MTC para que possam superar a tendência já naturalizada de classificar os alimentos por grupos (frutas, legumes etc ou proteína, carboidrato etc.) e de fato integrarem esses sabores novos às suas práticas docentes; sugeriram a produção de material didático para que eles possam levar essas informações e as referências para casa, facilitando a preparação futura de aulas agregando esse novo conhecimento; relataram o desafio de lidar com a integração das dificuldades das práticas alimentares dos alunos (como descrito anteriormente no texto) com o conteúdo curricular trabalhado em sala de aula. Além da produção do material, outra questão importante é a elaboração conjunta com esses professores de oficinas que possam colaborar no enfrentamento deste desafio relativo às práticas alimentares dos alunos. 
A partir das dinâmicas da oficina, foi possível observar que a primeira etapa estimulou a integração de cada um consigo mesmo. A segunda etapa conectou os professores às suas memórias. A terceira etapa deu espaço para reflexões sobre o trabalho docente e seus desafios cotidianos. A quarta etapa foi um espaço para o contato com uma maneira nova de olhar e classificar os alimentos. A última etapa de apresentação musical poderia ter sido precedida de degustação de alimentos com diferentes texturas (produzindo diferentes sons) para complementar a experiência sonora. Assim como seria importante acrescentar uma atividade de degustação para percepção dos sabores naturais dos alimentos para elucidar de forma mais adequada a visão oriental sobre os sabores dos alimentos e sua relação com a saúde.

Foi possível observar o potencial da arte no despertar da sensibilidade dos professores, abrindo caminhos para a elaboração de atividades de ensino-aprendizagem que articulem mais o conteúdo curricular a questões relevantes para a vida e saúde dos alunos.

Foi uma experiência de saber e de sabor. Sobretudo, uma experiência do saber sensível.

\title{
Alimentation, Arts and Science Education: links to teacher training
}

\begin{abstract}
The importance of the senses and the appreciation of the flavors are of utmost importance for Alimentation in the tasting or food preparation. Currently we live in a visual and auditory culture that subjugates experiments involving proximity, as touch, smell and taste. We must invest in educational activities that recover the pleasure of appreciation of natural foods's flavors. School is a useful space for such purpose. This work aims to compose theoretical discussion for the proposal of Education of the senses, presenting as an example of this practice an experience of a science teacher training workshop. Different forms of arts acted as mediators to stimulate awareness of the senses. During the stages of the activity the teachers were surprised with new perceptions of flavors and sensations and with the different dimensions of the Alimentation. They also exposed the challenges to articulate in their teaching practices the theme presented in the workshop.
\end{abstract}

Key words: Food education. Education of the senses. Science teaching. Teacher training. Art workshop.

\section{Alimentación, artes y ciencias: articulación para la formación del profesorado}

Resumen: La exaltación de los sentidos y la apreciación de los sabores son extremadamente importantes para la alimentación, ya sea en la degustaci- 
ón o en la preparación de alimentos. Hoy vivimos en una cultura visual y auditiva que subyuga las experiencias relacionadas con la cercanía, como tocar, oler y saborear Es necesario invertir en acciones educativas que rescaten el placer de disfrutar los sabores de los alimentos naturales, siendo la escuela un espacio fructífero para tal fin. Este trabajo tiene como objetivo componer una discusión teórica para la propuesta de la Educación de los sentidos, presentando como ejemplo de esta práctica una experiencia de un taller de formación de profesores de ciencias. Las diferentes formas de las artes actuaron como mediadores para estimular la sensibilización. Durante las etapas de la actividad, los maestros quedaron sorprendidos por las nuevas percepciones de sabores y sensaciones, con las diferentes dimensiones de los alimentos y expusieron los desafíos para articular en sus prácticas docentes el tema presentado en el taller.

Palabras clave: Educación alimentaria. Educación sensorial. Enseñanza de ciências. Formación de professores. Taller de artes.

\section{Referências}

AHIMA, R. S.; ANTWI, D. A. Brain regulation of appetite and satiety. Endocrinology and metabolism clinics of North America, Philadelphia, v. 37, n. 4, p. 811-823, 2008.

AHN, Y.-Y. et al. Flavor network and the principles of food pairing. Scientific Reports, New York, v. 1, n. 196, 2011.

ALVES, R. A educação dos sentidos e mais. Campinas: Verus, 2005.

BARBOSA, N. V. et al. Alimentação na escola: desafios e possibilidades. Ciência \& Saúde Coletiva, Rio de Janeiro, v. 18, n. 4, p. 937-945, 2013.

BRASIL. Conselho Nacional de Segurança Alimentar e Nutricional. Divulgadas orientações sobre $5^{\text {a }}$ Conferência Nacional. Brasília, DF: 20 jan. 2015. Disponível em: http://www4.planalto.gov.br/consea/ comunicacao/noticias/2015/janeiro/divulgadas-orientacoes-sobre-5aconferencia-nacional. Acesso em: 23 jun. 2020.

BRASIL, Ministério da Educação e do Desporto. Secretária de Educação Fundamental. Parâmetros curriculares nacionais: arte. Brasília, DF: MEC: SEF, 1997. Disponível em: http://portal.mec.gov.br/seb/arquivos/pdf/ livro06.pdf Acesso em: 28 out. 2019.

BRASIL. Ministério do Desenvolvimento Social e Combate à Fome. Marco de referência de educação alimentar e nutricional para as políticas públicas. Brasília, DF: MDS; 2012. Disponível em: http://www.cfn. org.br/index.php/marco-de-referencia-de-educacao-alimentar-enutricional/ Acesso em: 10 de out. 2019.

BRASIL. Ministério da Educação. Secretaria de Educação Básica. Secretaria de Educação Continuada, Alfabetização, Diversidade e Inclusão. Secretaria de Educação Profissional e Tecnológica. Conselho Nacional da Educação. Câmara Nacional de Educação Básica. Diretrizes Curriculares Nacionais Gerais da Educação Básica. Brasília, DF: MEC: SEB: DICEI, 2013. 
BRASIL. Ministério da Saúde. Secretaria de Atenção à Saúde. Departamento de Atenção Básica. Guia alimentar para a população brasileira / Ministério da Saúde, Secretaria de Atenção à Saúde, Departamento de Atenção Básica. 2. ed., Brasília, DF: MS, 2014. Disponível em: http://bvsms.saude.gov.br/bvs/publicacoes/guia_ alimentar_populacao_brasileira_2ed.pdf Acesso em: 29 de set. 2019.

BRASIL. Ministério da Saúde. Secretaria de Atenção à Saúde.

Departamento de Atenção Básica. Política nacional de práticas integrativas e complementares no SUS: atitude de ampliação de acesso / Ministério da Saúde. Secretaria de Atenção à Saúde. Departamento de Atenção Básica. 2. ed. Brasília, DF: MS, 2015. Disponível em: http:// bvsms.saude.gov.br/bvs/publicacoes/pnpic.pdf Acesso em: 12 set. 2019.

CARVALHO, D. B. A crise dos sentidos: modernidade líquida e o esvaziamento da experiência sensorial. Cadernos do PET Filosofia, Teresina, v. 2, n. 3, 2011.

CONTRERAS, J..; GRACIA, M. Alimentação, sociedade e cultura. Rio de Janeiro: Editora FIOCRUZ, 2011.

FAHRNOW, I. M.; FAHRNOW, J. Os cinco elementos na alimentação equilibrada. A arte da vida e da culinária segundo a medicina tradicional chinesa. São Paulo: Ágora, 2003.

FERNANDEZ, P. M..; OLIVEIRA, D. Descrição das noções conceituais sobre os grupos alimentares por professores de $1^{\text {a }}$ a $4^{\mathrm{a}}$ série: a necessidade de atualização dos conceitos. Ciência \& Educação, v. 14, n. 3, p. 451-66, 2008.

FIGUEIRA-OLIVEIRA, D. et al. Ciência e arte: uma proposta de aprendizagem no âmbito do ensino de biociências e saúde. In: ENCONTRO NACIONAL DE PESQUISA EM EDUCAÇÃO EM CIÊNCIAS. 14., 2007, Florianópolis. Anais [...] Florianópolis: ABRAPEC, 2007. p. 1-12. Disponível em: http://www.nutes.ufrj.br/abrapec/ vienpec/CR2/p409.pdf Acesso em: 10 ago. 2019.

FIGUEIRA-OLIVEIRA, D..; ROCQUE, L. R.; MEIRELLES, R. M. S. Ciência e arte: um "entre-lugar" no ensino de biociências e saúde. In: ENCONTRO NACIONAL DE PESQUISA EM EDUCAÇÃO EM CIÊNCIAS. 7., Florianópolis, 2009. Anais [...] Florianópolis: ABRAPEC, 2009. Disponível em: http://posgrad.fae.ufmg.br/posgrad/viienpec/ pdfs/921.pdf Acesso em: 9 ago. 2019.

FREITAS, E. O. O.; MARTINS, I. Transversalidade, formação para a cidadania e promoção da saúde no livro didático de ciências. Ensino, Saúde e Ambiente, Niterói, v. 1, n. 1, p. 12-28, ago. 2008.

GARCIA, R. W. D. Representações sociais da comida no meio urbano: algumas considerações para o estudo dos aspectos simbólicos da alimentação. Revista Cadernos de Debate, Campinas, v. 2, p. 12-40, 1994. 
JOMORI, M. M.; PROENÇA, R. P. da C.; CALVO, M. C. M. Determinantes de escolha alimentar. Revista de Nutrição, Campinas, v. 21, n. 1, p. 63-73, jan./fev. 2008.

LENZI, H. Ciência com emoção e arte. In: ARAÚJO-JORGE, T. C. (org.). Ciência e arte: encontros e sintonias. Rio de Janeiro. Editora Senac Rio, 2004.

LOBO, M. A. Textos de divulgação científica: recursos para promover a educação alimentar e nutricional em aulas de ciências? 2014. 180 f. Tese (Doutorado em Educação em Ciências e Saúde) - Núcleo de Tecnologia Educacional para a Saúde, Universidade Federal do Rio de Janeiro. Rio de Janeiro. 2014.

LOPES, T. Luz, arte, ciência... ação! História, Ciências, Saúde Manguinhos, Rio de Janeiro, v. 12 (suplemento), p. 401-18, out./dez. 2005.

LOUZADA, M. L. da C. et al. Alimentos ultraprocessados e perfil nutricional da dieta no Brasil. Revista de Saúde Pública, São Paulo, v. 49, p. 38, 2015.

MACHADO, R. N.; WINOGRAD, M. A importância das experiências táteis na organização psíquica. Estudos e Pesquisas em Psicologia, Rio de Janeiro, v. 7, n. 3, p. 462-476, dez. 2007.

MINAYO, M. C. de S. O desafio do conhecimento. Pesquisa qualitativa em saúde. São Paulo: Hucitec; Rio de Janeiro: Abrasco, 1992.

MOHR, A. A saúde na escola: análise de livros didáticos de $1^{\text {a }}$ a $4^{\text {a }}$ séries. Cadernos de Pesquisa, São Paulo, n. 94, p. 50-57, 1995.

NASCIMENTO, A. de A. B. S. Comida: prazeres, gozos e transgressões. 2. ed., Salvador: EDUFBA, 2007.

PACHECO, S. S. Q. de M. Alimentação, cultura e educação: em busca de uma abordagem transdisciplinar. Revista da FAEEBA: educação e contemporaneidade, Salvador, v. 12, n. 19, p. 181-188, 2003.

PERFECT SENSE. Produção de David Mackenzie. Reino Unido: Sigma Films, 2011. 1 disco DVD (92 min).

PERINI, M. Terapia dietética chinesa. São Paulo: Edições Loyola. 2003.

POLLAN, M. Cozinhar: uma história natural da transformação. Rio de Janeiro: Intrínseca, 2014.

SAVARIN, B. Fisiologia do gosto. São Paulo: Companhia das Letras, 1995.

SAWAYA, A. L.; FILGUEIRAS, A. "Abra a felicidade"? Implicações para o vício alimentar. Estudos Avançados, São Paulo, v. 27, n. 78, 2013.

SENTIDOS DOS SABORES. [Compositores]: Rafael Garcia e Mônica Lobo. [intérprete]: Rafael Garcia. Rio de Janeiro: 2015. Arquivo digital (4min13s).

SERRES, M. Os cinco sentidos. Rio de Janeiro: Bertrand Brasil. 2001. 
SILVA, M. R.; SAKAMOTO, J.; GALIAN, D. M. C. A cultura estética e a educação do gosto como caminho de formação e humanização na área da saúde. Trabalho educação e saúde, Rio de Janeiro, v. 12, n. 1, p. 15-28, 2014.

VIDAL, A. A poesia é para comer: iguarias para o corpo e para o espírito/seleção de poemas Ana Vidal. São Paulo, Editora Babel, 2011.

Submetido em 12/11/2019. Aceito em 07/07/2020. 